\title{
Geoquímica de reservatórios
}

\author{
Joelma Pimentel Lopes ${ }^{1}$, Mário Duncan Rangel ${ }^{2}$ Erica Tavares de Morais ${ }^{3}$ \& \\ Hélen G. M. de Aguiart
}

\begin{abstract}
Resumo A Geoquímica de Reservatórios é uma área de conhecimento relativamente nova das Geociências, que estuda as variações na composição molecular dos fluidos contidos em reservatórios de petróleo, com o objetivo principal de entender as origens destas variações e usá-las para melhorar as estratégias de exploração e, mais particularmente, de produção e desenvolvimento de campos de petróleo. As heterogeneidades composicionais na coluna de fluidos em escala lateral, da ordem de quilômetros, sugerem a direção de preenchimento, ou a direção do fluxo de água em campos com óleo biodegradado, ou ainda a presença de grandes barreiras ao fluxo de fluidos no reservatório. Por outro lado, as heterogeneidades verticais sugerem que os reservatórios podem estar verticalmente compartimentados. As alterações composicionais do petróleo em reservatórios ocorrem devido à natureza do fluido variar física e quimicamente com o aumento da evolução térmica, processos de alteração secundária do petróleo (processos que ocorrem localmente com o óleo já no reservatório) como biodegradação e water washing, ou ainda por contribuição de mais de uma rocha geradora durante o preenchimento do reservatório. Uma vez que o reservatório já está completamente preenchido, forças direcionadas por densidade e por difusão molecular procuram eliminar estas variações composicionais, na tentativa de alcançar o equilíbrio químico e mecânico na coluna de óleo (England 1990). Casos de sucessos com a utilização da Geoquímica de Reservatórios indicam que é uma ferramenta eficiente e que pode ser usada para auxiliar na descrição, avaliação e desenvolvimento de reservatórios, assim como na exploração e produção de campos de petróleo por um custo relativamente baixo. O principal alvo do artigo é apresentar o estado-da-arte da Geoquímica de Reservatório objetivando informar e difundir o conhecimento teórico entre os geocientistas brasileiros, em especial àqueles que atuam no meio acadêmico.
\end{abstract}

Palavras-chave: geoquímica, reservatórios, composicional, compartimentação, produção.

\begin{abstract}
Reservoir Geochemistry. Reservoir Geochemistry has many important practical applications during petroleum exploration, appraisal and development of oil fields. The most important uses are related to providing or disproving connectivity between reservoirs of a particular well or horizon. During exploration, reservoir geochemistry can indicate the direction of oil filling, suggesting the most appropriate places for drilling new wells. During production, studies of variations in composition with time and determination of proportions of commingled production from multiple zones, may also be carried out. The chemical constituents of petroleum in natural reservoirs frequently show measurable compositional variations, laterally and vertically. Due to the physical and chemical nature of petroleum changes with increasing maturity (or contribution of a second source during the filling process), lateral and vertical compositional variations exist in petroleum columns as reservoir filling is complete. Compositional variation can also be introduced by biodegradation or water washing. Once the reservoir is filled, density driven mixing and molecular diffusion tend to eliminate inherited compositional variations in an attempt to establish mechanical and chemical equilibrium in the petroleum column (England, 1990). Based on organic geochemical analysis it is possible to define these compositional variations among reservoirs, and use these data for developing of petroleum fields and for reservoir appraisal. Reservoir geochemistry offers rapid and low cost evaluation tools to aid in understanding development and production problems. Moreover, the applied methodology is relatively simple and gives reliable results, and can be performed routinely in any good geochemical laboratory at a relatively low cost.
\end{abstract}

Keywords: Reservoir geochemistry, compositional heterogeneities, oil fingerprint.

INTRODUÇÃO A Geoquímica Orgânica de petróleo inicialmente visava somente apoiar a exploração, através da caracterização dos petróleos e mapeamento das rochas potencialmente geradoras. Posteriormente, passou a ser empregada também para a avaliação da continuidade de reservatórios de petróleo com o objetivo de identificar heterogeneidades composicionais a partir de parâmetros obtidos de amostras de óleo.

1 - Petrobras/CENPES/PDEXP/GEOQ, Cid. Universitária, Rio de Janeiro (RJ), Brasil, E-mail: joelma.lopes@petrobras.com.br

2 - Petrobras/CENPES/PDEXP/GEOQ, Cid. Universitária, Rio de Janeiro (RJ), Brasil. E-mail: mduncan@petrobras.com.br

3 - Petrobras/CENPES/PDEXP/GEOQ, Cid. Universitária, Rio de Janeiro (RJ), Brasil. E-mail: ericat@petrobras.com.br

4 - Fundação GORCEIX. Vila Itacolomy, Ouro Preto (MG), Brasil. E-mail: helenaguiar.GORCEIX@petrobras.com.br 
Este novo enfoque, iniciado no final da década de oitenta, foi possível a partir do advento de novas técnicas investigativas relacionadas a análises de cromatografia gasosa assim como da utilização de ferramentas estatísticas como as Análises de Agrupamento (cluster analysis) e Componentes Principais (PCA). Por conseguinte, o método de fingerprint whole oil, desenvolvido por Kaufman et al. (1990) tornou possível a identificação da variação composicional em amostras de óleo a partir do resultado de cromatografia gasosa.

Uma das observações chaves que direcionam os geoquímicos de reservatórios é que os fluidos (água, gás, óleo) dos reservatórios apresentam geralmente heterogeneidades composicionais, tanto em escala lateral quanto vertical.

Ainda pouco conhecida junto aos que labutam em Geociências, a Geoquímica de Reservatório tem como objetivo principal entender as origens das heterogeneidades do petróleo no reservatório e usá-las para melhorar as estratégias de exploração e, mais particularmente, de produção e desenvolvimento de campos de petróleo. Uma segunda aplicação da Geoquímica de Reservatórios é utilizar o conhecimento de química do petróleo para entender de que maneira o petróleo interage com a rocha e a água e, portanto, como estes influenciam sua molhabilidade, viscosidade e a formação de feições tipo tar mats em reservatórios. Embora a Geoquímica de Reservatório possa ser considerada por si só uma subdisciplina dentro da Geologia do Petróleo, é importante fazer a associação entre ela e a Geologia e a Engenharia de Reservatórios. Na verdade, os estudos de Geoquímica de Reservatório devem ser integrados com os dados de geologia e engenharia para que os benefícios sejam os mais amplos possíveis (Larter \& Aplin, 1995).

Apresenta-se nesse texto um breve histórico, os fundamentos, os principais métodos empregados e estudos de dois casos relacionados à Geoquímica de Reservatório. Com isto pretende-se oferecer elementos que possam facilitar a compreensão e estimular a utilização dessa área de conhecimento.

Histórico Historicamente, o papel da geoquímica orgânica na indústria do petróleo tem sido direcionado para a área de exploração, quer identificando a rocha geradora de petróleo, quer estimando sua evolução térmica, ou determinando o volume de petróleo gerado. Desde 1985, entretanto, o foco dos geoquímicos de petróleo tem sido ampliado na direção a produção e a problemas associados aos reservatórios de petróleo (Larter \& Aplin, 1995).

Slentz (1981) foi o primeiro autor que publicou a técnica de Geoquímica de Reservatórios para avaliar a continuidade de reservatórios, ele propôs que a composição de um óleo era como uma "impressão digital" característica de um reservatório específico. Embora, Slentz (1981) tenha sido a primeira publicação, esta técnica vinha sendo utilizada por diversos geoquímicos de outras companhias. Somente em 1990, Kaufman et al. (1990), em um trabalho de três autores da Chevron, desemvolveram detalhes metodológicos da técnica previamente descrita por Slentz (1981). Posteriormente, Lindberg et al. (1990), Hwang \& Baskin (1994), Hwang et al. (1994), Sundararaman et al. (1995), Ross \& Ames (1988) e Nederlof et al. $(1994,1995)$ utilizaram a técnica de Geoquímica de Reservatórios para avaliar a continuidade de reservatórios.

A primeira coletânea de trabalhos específicos relacionados à Geoquímica de Reservatórios foi a publicação especial da Sociedade de Geologia de Londres em 1995, cujos editores foram J.M. Cubitt e W.A. England intitulada: The Geochemistry of Reservoirs. Este trabalho agrega uma série de artigos de autores diversos abordando tópicos distintos de interesse desta nova subdisciplina da geoquímica orgânica. Desta data em diante, a quantidade de publicações aumentou consideravelmente, assim como o número de conferências associadas a este tema. Atualmente, a Geoquímica de Reservatório é uma ferramenta de rotina usada na indústria do petróleo.

Trabalhos de grande relevância para o tema também foram realizados por: Thompson $(1983 ; 1988)$ que fez uma classificação de petróleos empregando os hidrocarbonetos leves (compostos $\mathrm{C}_{7}$ ) e apresentou um modelo de migração e fracionamento evaporativo de condensados em sistemas deltaicos; Mango (1990a; 1990b; 1994; e 1997) que abordou a origem dos hidrocarbonetos leves (compostos $\mathrm{C}_{7}$ ) no petróleo e faz interpretações associadas à sua origem e evolução térmica; Halpern (1995) que apresentou o desenvolvimento e aplicação de diagramas de estrela com os hidrocarbonetos leves; e Jarvie \& Walker (1997) que fazem uma correlação de óleos e rochas geradoras usando resultados de extração térmica com hidrocarbonetos leves identificados por cromatografia gasosa.

No Brasil, técnicos do Centro de Pesquisas da Petrobras (CENPES), foram os pioneiros na utilização da Geoquímica de Reservatórios (Cerqueira \& Trindade, 1995). Inicialmente, foram abordados campos em franca atividade de desenvolvimento na Bacia Potiguar. Posteriormente, também foram objetos de estudo os campos de petróleo das bacias de Campos, Espírito Santo, e do Recôncavo. Em 2003, a primeira tese de mestrado abordando especificamente este tema foi desenvolvida por Rangel (2003), o que consagrou a Geoquímica de Reservatórios no Brasil.

Objetivos A Geoquímica de Reservatórios tem como alvo à caracterização dos fluidos armazenados em determinada acumulação de petróleo (água, óleo, e gás), identificar e explicar sua variabilidade composicional e as interações com as rochas reservatórios. Estas heterogeneidades refletem tanto a geologia regional quanto em escala de reservatório, e podem ser empregadas tanto como uma ferramenta descritiva do próprio reservatório, quanto para a delimitação e o desenvolvimento de uma acumulação, e também para a exploração regional. Trata-se de uma área de conhecimento que se coloca entre a Geologia e a Engenharia de Reservatórios (Larter \& Aplin, 1995). 
Não menos importantes são os aspectos relacionados ao apoio à produção de determinado campo de petróleo. Em poços com completação dupla (aqueles onde dois reservatórios distintos estão produzindo óleo através de uma única coluna de produção) a Geoquímica de Reservatórios pode ser empregada para estimar a participação de cada um dos intervalos sem interrupção da produção. Também associada à produção está a possibilidade de se investigar a variação da qualidade do óleo produzido ao longo do tempo em determinado poço ou área do campo. Outra possível aplicação, ainda na área da produção, é a identificação de ruptura na coluna de produção.

Atualmente, novos objetivos foram agregados à Geoquímica de Reservatórios. O primeiro é dar suporte a área ambiental através da possibilidade de identificação da origem de vazamento de óleo, quer seja pela identificação do poço fonte do vazamento em um campo, ou de que campo provém o vazamento em determinada área. O segundo é identificar e mensurar, através de cromatografia gasosa (CG), a quantidade de aditivo orgânico adicionado ao fluido de perfuração de poços.

Fundamentos e processos ligados à Geoquímica de Reservatórios O petróleo inicialmente preenche um reservatório através dos poros com a menor pressão de entrada, que está freqüentemente relacionada com as litologias mais grosseiras. A migração contínua conduz a um gradativo aumento na força de empuxo o que leva ao preenchimento dos poros menores, além do trapeamento da água de formação residual. O preenchimento da acumulação ocorre a partir de determinada direção, e avança por meio de frentes de migração, deslocando o fluido previamente armazenado, inclusive o óleo, tanto lateralmente quanto verticalmente, dificultando neste caso a mistura da coluna de óleo (England \& Mackenzie, 1989; England, 1990) e favorencendo o aparecimento de heterogeneidades composicionais nos fluidos do reservatório.
A variação composicional do petróleo ocorre devido a natureza do fluido variar física e quimicamente com o aumento da evolução térmica, ou se uma segunda rocha geradora de petróleo torna-se matura durante o processo de preenchimento do reservatório, ou ainda devido a processos de alteração secundária do petróleo (processos que ocorrem localmente com o óleo já no reservatório) como biodegradação (alteração do óleo cru por bactérias) e water washing (remoção de compostos solúveis em água) (England, 1990; Fig. 1).

Uma vez que o reservatório já está completamente preenchido, forças direcionadas por densidade e difusão molecular procuram eliminar estas variações composicionais, na tentativa de alcançar o equilíbrio químico e mecânico na coluna de óleo. O efeito da temperatura, em tese, pode ser suficientemente grande para submeter uma instabilidade no perfil de densidade, conduzindo a convecção de toda a coluna de óleo minimizando o gradiente composicional (Stainforth 2004). No entanto, estudos teóricos mostram que o efeito da temperatura pode intensificar ou atenuar o efeito gravitacional (Firoozabadi et al. 1996; Firoozabadi 1999). Entretanto, alguns autores afirmam que a convecção térmica não é um mecanismo significativo para homogeneização de líquidos em reservatórios (Horstad et al. 1990; Hoier \& Whitson 2001).

\section{MECANISMOS DE MISTURA DO ÓLEO NO RESER- VATÓRIO Os fluidos nos reservatórios tendem a se homogeneizar via difusão molecular e devido a forças direcionadas por densidade visando um estado de equi- líbrio mecânico e composicional (England et al. 1995; England, 1990).}

Forças Direcionadas por Densidade Variações na densidade do fluido geralmente são provenientes da história de preenchimento do reservatório. Os fluidos inicialmente expelidos de uma rocha geradora são líquidos relativamente densos. Com o aumento da ma-

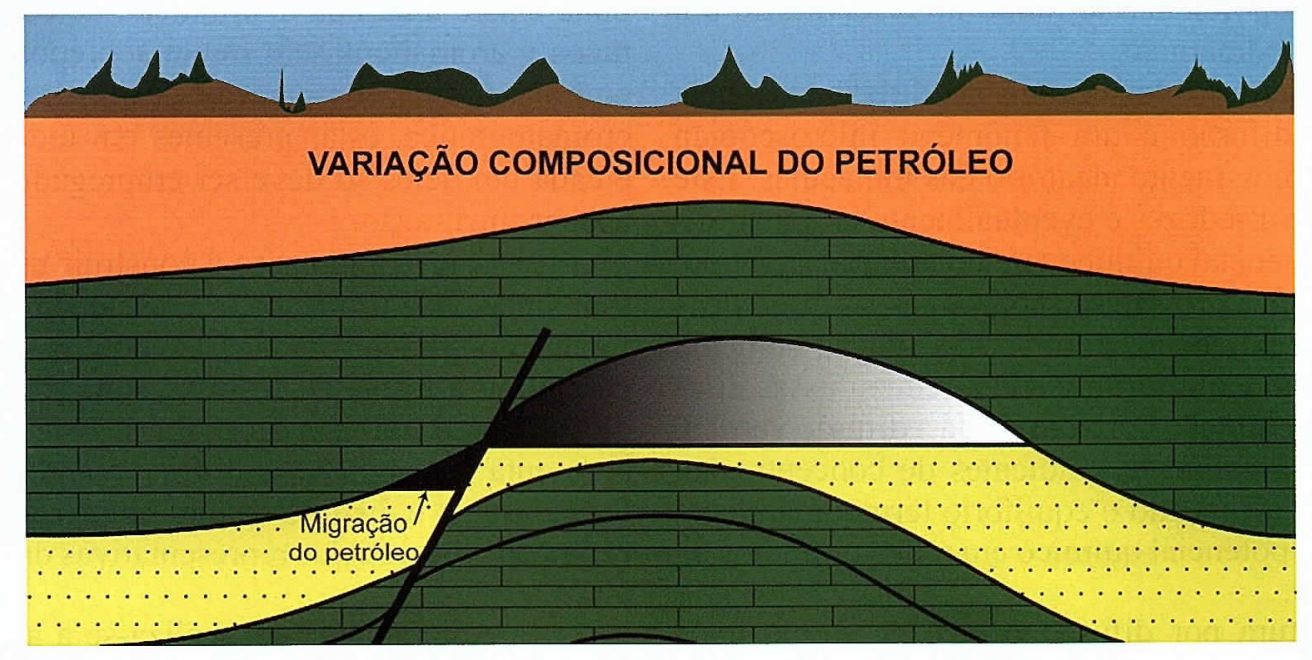

Figura 1 - Modelo esquemático de migração lateral do óleo preenchendo uma estrutura. 
turação térmica da rocha geradora, o fluido expelido passa a ser mais leve (menor densidade), assim, cada compartimento do reservatório pode ser preenchido por diferentes proporções de fluidos com diferentes graus de evolução térmica e densidades. Outras variações na densidade podem ser causadas por processos de alteração pós-acumulação nos reservatórios, como biodegradação e water washing, que tornam o fluido mais denso.

Dois fluidos de diferentes densidades, referenciados a mesma profundidade, oriundos de reservatórios justapostos só permanecem heterogêneos se houver uma barreira que os isole. Caso contrário, as forças direcionadas pela densidade tenderão a eliminar estas diferenças e promover uma coluna de óleo composicionalmente homogênea.

O produto da mistura direcionada por densidade pode não ser um fluido de densidade homogênea. Quando uma coluna de óleo é subordinada ao campo gravitacional é estabelecido um gradiente de concentração termodinamicamente estável. Este é um efeito termodinâmico em que uma maior concentração de componentes mais densos $\left(\mathrm{C}_{10^{+}}\right)$se localizam na base enquanto os componentes menos densos (metano, etano, etc) no topo da coluna de óleo (England 1990).

Outro fator importante é a relação entre a taxa de mistura direcionada por densidade e o tempo decorrido desde o preenchimento do reservatório (England 1990). O tempo necessário para esta homogeneização depende do tipo de fluido, das condições permoporosas do reservatório e da diferença inicial de densidade entre os fluidos (Smalley et al. 2004).

Difusão Molecular A difusão pode ser vista como um processo no qual a concentração tende a se igualar em todos os pontos do sistema, as moléculas tendem a migrar de uma região de concentração elevada para a região de menor concentração, com o passar do tempo, ou seja, é um processo no qual a diferença de concentração é reduzida através de um fluxo espontâneo da matéria, sendo o mecanismo de transferência de massa que tende a proporcionar ao fluido no reservatório um equilíbrio termodinâmico.

Ao contrário do mecanismo direcionado pela densidade, a difusão é um fenômeno microscópico causado pelo movimento aleatório das moléculas. Este processo tende a reduzir, e eventualmente eliminar, diferenças do potencial químico em um volume de fluido. Se a temperatura e pressão são constantes, as diferenças horizontais no potencial químico são função somente da concentração e a difusão tende a reduzir essas diferenças de concentração horizontais. Já a difusão vertical induz gravitacionalmente gradientes de concentração, desde que seja alcançado o equilíbrio termodinâmico e estabelecido o potencial químico em todos os pontos da coluna de óleo.

A mistura por difusão ocorre de forma mais rápida em uma coluna de óleo individual e de forma muito lenta entre diferentes poços, sendo considerado o processo mais lento quando comparado a outros processos de mistura. Metano e componentes $\mathrm{C}_{12}$ apresentam os menores tempos de difusão (entre 1 e 10 milhões de anos), enquanto moléculas maiores, como os componentes $\mathrm{C}_{200}$, em óleos viscosos necessitam de muito mais tempo para a homogeneização (entre 10 a 100 milhões de anos) quando considerada uma distância padrão de $1000 \mathrm{~m}$ (Smalley et al. 2004).

MÉTODOS Os procedimentos empregados são baseados nos métodos geoquímicos desenvolvidos entre os anos de 1970 e 1980, modificados para atender a Geoquímica de Reservatórios em alguns novos propósitos.

De acordo com Slentz (1981) a composição de um óleo preserva a "impressão digital" característica de um reservatório específico. Essas variações composicionais entre petróleos podem ser observadas através de um perfil cromatográfico (Fig. 2a), que permite a análise de abundâncias distintas dos compostos que estão distribuídos entre os hidrocarbonetos lineares também conhecidos como parafinas normais (Fig. 2b).

Kaufman et al. (1990) desenvolveram um método sensível para reconhecer as diferenças em cromatogramas gasosos da fração leve do petróleo conhecidocomo fingerprint whole oil.

$\mathrm{O}$ método visa procurar diferenças entre os compostos menos abundandantes como as parafinas ramificadas, os compostos naftênicos (cicloalcanos), e aromáticos (Fig. 2b) pois em geral, o cromatograma gasoso de óleo total (whole oil) como um todo não tem suficiente precisão para distinguir óleos de composição similar.

A seguir são descritas as várias etapas previstas para a utilização deste método. Primeiramente, são numerados os picos seqüencialmente até a última $n$-parafina desejada (Fig. 3a). Então, são selecionados tantos pares de picos adjacentes quanto se consiga (normalmente 12 já são suficientes). Em seguida são calculadas razões entre suas alturas, ou suas áreas (Fig. 3b). Os picos são selecionados principalmente na faixa entre as parafinas lineares com oito e vinte átomos de carbono, onde existe uma boa distribuição de compostos naftênicos e aromáticos sem muita sobreposição. Os picos empregados na comparação devem ter boa resolução cromatográfica, estar presentes em todas as amostras, e cada um deles só deve ser empregado no cálculo de apenas uma razão.

O próximo passo é construir um diagrama estrela onde cada razão será representada em um eixo diferente do gráfico (Fig. 3c). Os pontos são ligados para configurar a forma de "estrela", que será característica de cada óleo, ou grupo de óleos. Este tipo de gráfico apresenta distribuição uniforme quando o reservatório for contínuo, e distinto quanto houver variação significativa entre as estrelas representativas daquele grupo de óleos.

Adicionalmente, realiza-se a análise de agrupamento (Cluster Analysis), que consiste na formação de grupos de indivíduos ou elementos, tomando como base medidas de similaridade, que por sua vez, são cal- 


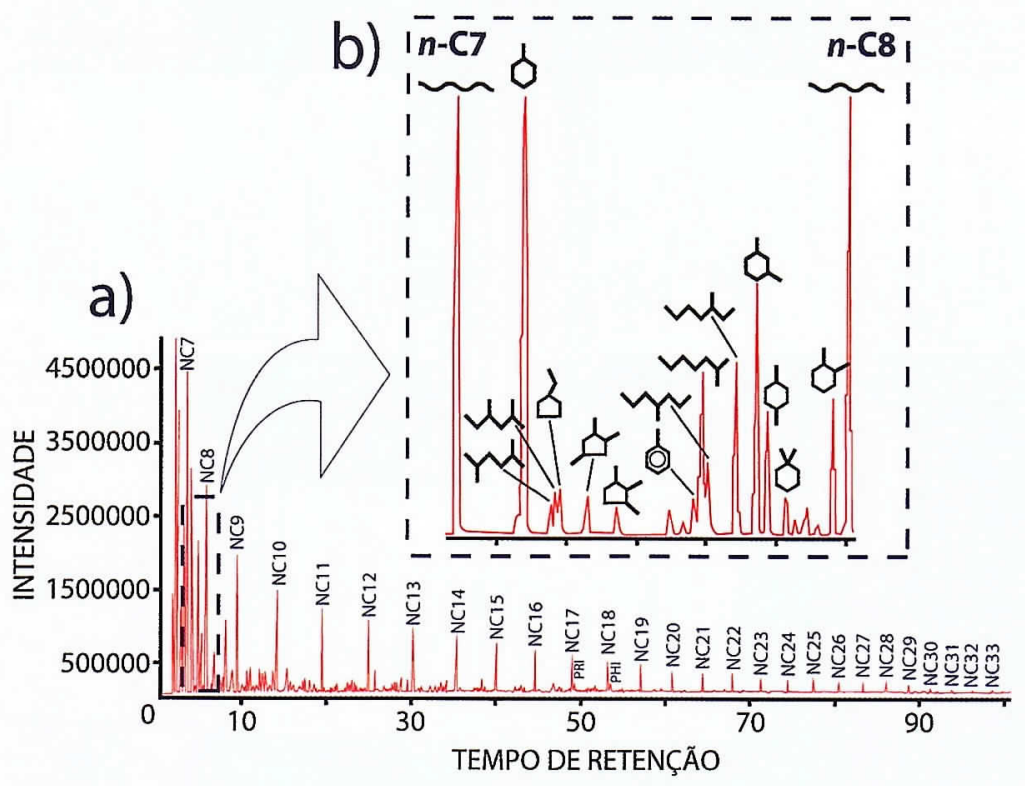

Figura 2 - Exemplo de perfil cromatográfico; (a) Cromatograma do óleo total (whole oil); (b) Detalhe da distribuição de compostos entre as parafinas normais: parafinas ramificadas, compostos naftênicos e aromáticos.

culadas com base em uma lista de variáveis fornecidas, neste caso as razões calculadas entre os valores de picos adjacentes. Cada caso constitui um grupo independente, em seguida, formam-se novos grupos pela fusão de grupos existentes, baseado na similaridade ou dissimilaridade entre estes grupos iniciais. Os resultados são fornecidos na forma de dendogramas, onde as amostras semelhantes, segundo as variáveis escolhidas, são agrupadas entre si. A suposição básica de sua interpretação é que quanto menor a distância entre os pontos, maior a semelhança entre as amostras (Fig. 3d). O fluxo geral deste procedimento resume-se em: (1) coleta das amostras, (2) análise cromatográfica, (3) seleção dos picos, (4) correlação dos óleos e (5) interpretação geológica.

$\mathrm{Na}$ década atual, a cromatografia gasosa tipo CARBURANE ${ }^{\circledR}$ foi implementada na Petrobras em substituição à cromatografia gasosa fingerprint whole oil originalmente utilizada por Kaufman et al. (1990), devido a primeira apresentar vantagens analíticas e interpretativas como será discutido posteriormente.

Embora a cromatografia gasosa seja a técnica analítica de maior valor agregado na avaliação de variações composicionais em petróleos, as análises geoquímicas tradicionais são adicionalmente utilizadas na interpretação dos dados. Os métodos analíticas são apresentados em seguida.

Métodos Analíticos Para estudos de Geoquímica Orgânica a amostra de óleo é primeiramente submetida às análises de determinação das propriedades físicas. Posteriormente, as amostras de óleo são caracterizadas geoquimicamente a partir de ensaios analíticos por cromatografia líquida (CL), cromato- grafia gasosa (CG) whole-oil ou CARBURANE®), e análise elementar da razão isotópica do carbono por espectrometria de massas (AE-RIEM). A análise por cromatografia líquida permite separar o óleo em três frações: hidrocarbonetos saturados, hidrocarbonetos aromáticos e compostos polares (resinas + asfaltenos). A fração de hidrocarbonetos saturados é analisada por cromatografia gasosa acoplada a espectrometria de massas (CGEM). A figura 4 apresenta o fluxograma das técnicas analíticas empregadas em estudos de Geoquímica de Reservatórios.

DETERMINAÇÃO DO GRAU API O grau API (American Petroleum Institute) é uma forma de expressar a densidade relativa de um óleo ou derivado. A escala API varia inversamente com a densidade relativa do óleo, ou seja, quanto maior a densidade relativa, menor o grau API e vice-versa. Por uma convenção, óleos com grau API maiores que $30^{\circ}$ são considerados leves; aqueles entre $30^{\circ}$ e $22^{\circ}$ médios; e aqueles com valores abaixo de $22^{\circ}$ são pesados (North, 1985). Entretanto, esses valores não são universais e podem variar.

A determinação do grau API de uma amostra de óleo é feita em um densitômetro digital, onde uma pequena parte da amostra (geralmente menos que $1 \mathrm{~mL}$ ) é introduzida dentro da célula de amostragem, com auxílio de uma seringa adequada, e com temperatura controlada. Um tubo oco em forma de U é forçado em oscilação harmônica, e esse período de oscilação depende da densidade da amostra no tubo. A freqüência de oscilação deve ser anotada, e a densidade da amostra é calculada com auxílio das constantes da célula pre- 

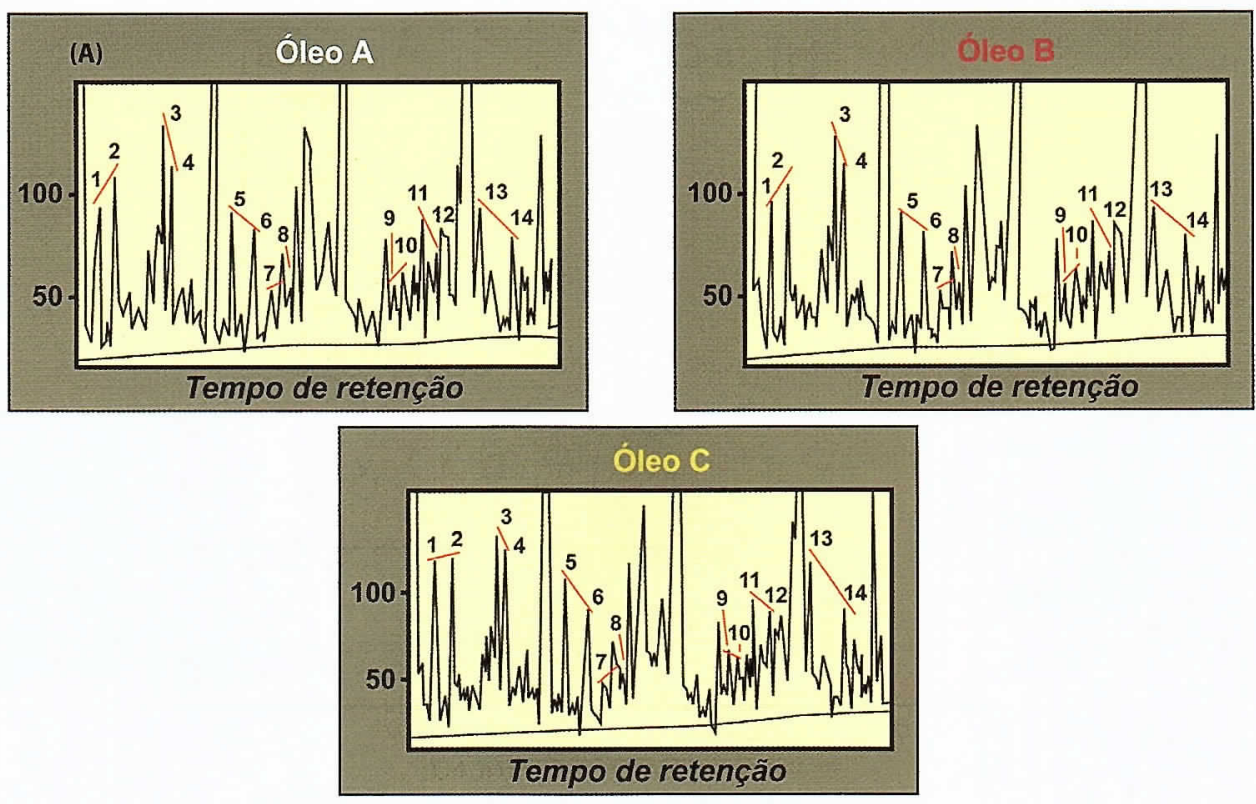

(B) RAZÕES ENTRE ALTURAS DE HC's
\begin{tabular}{|c|c|c|c|c|c|c|c|}
\hline ÓLEO & $1 / 2$ & $3 / 4$ & $5 / 6$ & $7 / 8$ & $9 / 10$ & $11 / 12$ & $13 / 14$ \\
\hline A & 0.84 & 1.17 & 1.15 & 0.89 & 0.82 & 0.71 & 1.33 \\
\hline B & 0.86 & 1.19 & 1.11 & 0.91 & 0.82 & 0.70 & 1.36 \\
\hline C & 0.99 & 1.09 & 1.29 & 0.72 & 1.09 & 0.86 & 1.56 \\
\hline
\end{tabular}
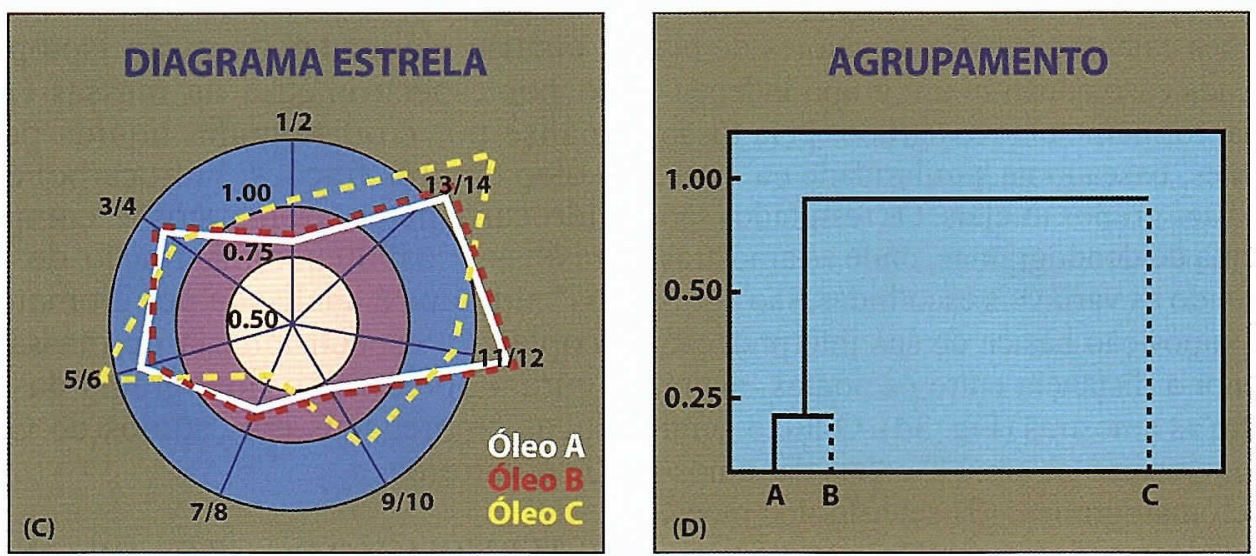

Figura 3 - Sequência da metodologia fingerprint whole oil desenvolvida por Kaufman et al. (1990). (a) São numerados os pequenos picos mensuráveis seqüencialmente, até a última n-parafina desejada, e selecionados tantos pares de picos adjacentes quanto se consiga, (b) São calculadas as razões entre suas alturas, ou suas áreas e reportadas em forma de tabela (c) Construção de um diagrama de estrela onde cada razão é representada em um eixo diferente do gráfico (d) Análise de agrupamento (Cluster Analysis), onde os resultados são fornecidos na forma de dendogramas.

viamente determinadas pela medição das freqüências de oscilação, quando a célula é preenchida com fluidos de calibração de densidade conhecida (água e ar). Os resultados são obtidos em $\mathrm{Kg} / \mathrm{m}^{3}$, a uma temperatura de referência de 15 ou $20^{\circ} \mathrm{C}$. A densidade medida a $15^{\circ} \mathrm{C}$ $\left(60^{\circ} \mathrm{F}\right)$ pode ser convertida em grau API através da fórmula (1):

$$
A P I=\frac{141,5}{\rho}-131,5
$$

CROMATOGRAFIA LÍQUIDA Este processo tem a finalidade de separar os componentes dos óleos nas frações parafinas (normais, ramificadas e cíclicas), os compostos aromáticos e compostos polares (resinas + asfaltenos). A separação é feita através da passagem da 


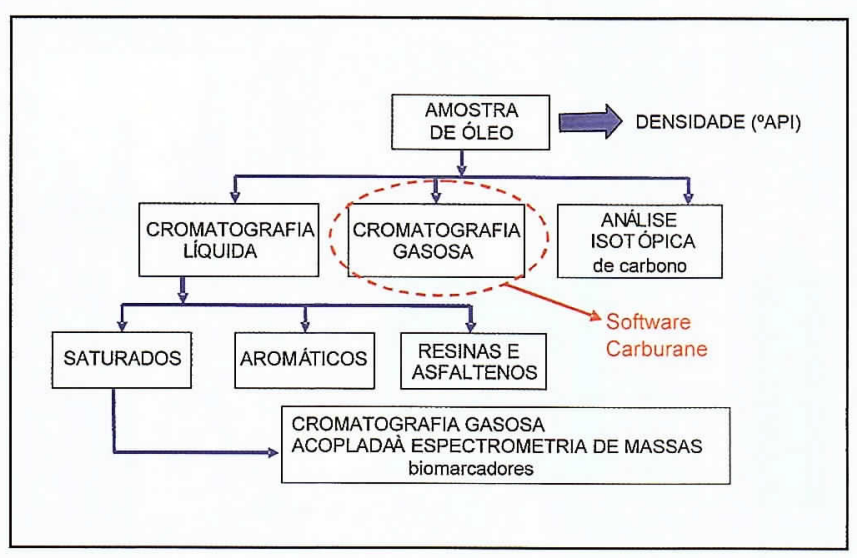

Figura 4 - Fluxograma das técnicas analíticas empregadas em estudos de Geoquímica de Reservatórios.

amostra de óleo diluída em um solvente ( $n$-hexano + padrão colestano), que é a fase móvel, por uma coluna de sílica, que é a fase estacionária. As diferentes frações irão percolar a coluna com velocidades distintas devido às interações moleculares entre os compostos carreados pela fase móvel interagindo com a fase estacionária. Os compostos polares ficam retidos nessa pré-coluna, passando apenas os hidrocarbonetos, que são encaminhados a uma coluna principal. Na coluna principal, as parafinas passam com o menor tempo de retenção. Existem dois frascos coletores específicos, um para as parafinas e outro para os aromáticos. As duas frações são posteriormente concentradas. As parafinas são registradas como um pico pelo sinal do detector UV (ultravioleta), que faz o registro por sinal eletrônico, e os aromáticos são registrados como dois picos concomitantes, gerados pelo sinal gerado no detector IR (índice de refração), que faz o registro pela diferença de polaridade do solvente. Os compostos polares que ficam retidos nas pré-colunas são pressurizados com etanol, extraídos, concentrados e armazenados em frascos separados, para o cálculo da composição da amostra analisada.

CROMATOGRAFIA GASOSA (WHOLE OIL) E CROMATOGRAFIA GASOSA (CARBURANE®) A técnica de cromatografia gasosa permite a separação e a identificação dos compostos mais abundantes em um petróleo, ou seja, as parafinas (principalmente as lineares e as ramificadas) e os aromáticos. Geralmente, os cromatogramas de óleos preservados apresentam picos predominantes representando as cadeias lineares e picos menores representando cadeias ramificadas, cíclicas e compostos aromáticos (Fig. 5).

Para a análise cromatografia gasosa de óleo total (whole oil), deve ser injetado $1 \mu 1$ da amostra diluída em diclorometano no cromatógrafo a gás. $\mathrm{O}$ injetor permite o controle da vazão de amostra injetada, e é mantido a $300^{\circ} \mathrm{C}$. Cada grupo de moléculas semelhantes é vaporizado e arrastado pelo gás inerte hélio, passando por um tubo capilar de metilsilicone de $30 \mathrm{~m}$ de comprimento e $0,25 \mathrm{~mm}$ de diâmetro interno, contendo uma fina película de fase estacionária. O tempo de saída dos grupos de compostos depende da afinidade que estes têm com a fase estacionária. As moléculas mais voláteis tendem a sair primeiro. Por isso, trabalha-se com uma rampa de aquecimento de $40^{\circ}$ a $320^{\circ} \mathrm{C}$, com taxa de aquecimento de $2,5^{\circ} \mathrm{C} / \mathrm{min}$, permitindo que os mais pesados saiam gradativamente com o aumento da temperatura. Ao sair da coluna, as moléculas são reconhecidas por um detector de ionização de chama (DIC), mantido a $340^{\circ} \mathrm{C}$, registrando picos para os grupos de moléculas (Fig. 6).

Para a aplicação desta metodologia alguns cuidados se fazem necessários. Primeiramente, o tempo decorrido entre a coleta e a análise deve ser o menor possível, ou que as amostras estejam bem acondicionadas e preservadas. A corrida cromatográfica deve ser feita no mesmo equipamento, empregando-se a mesma

\section{Exemplo de Cromatograma (Whole oil)}

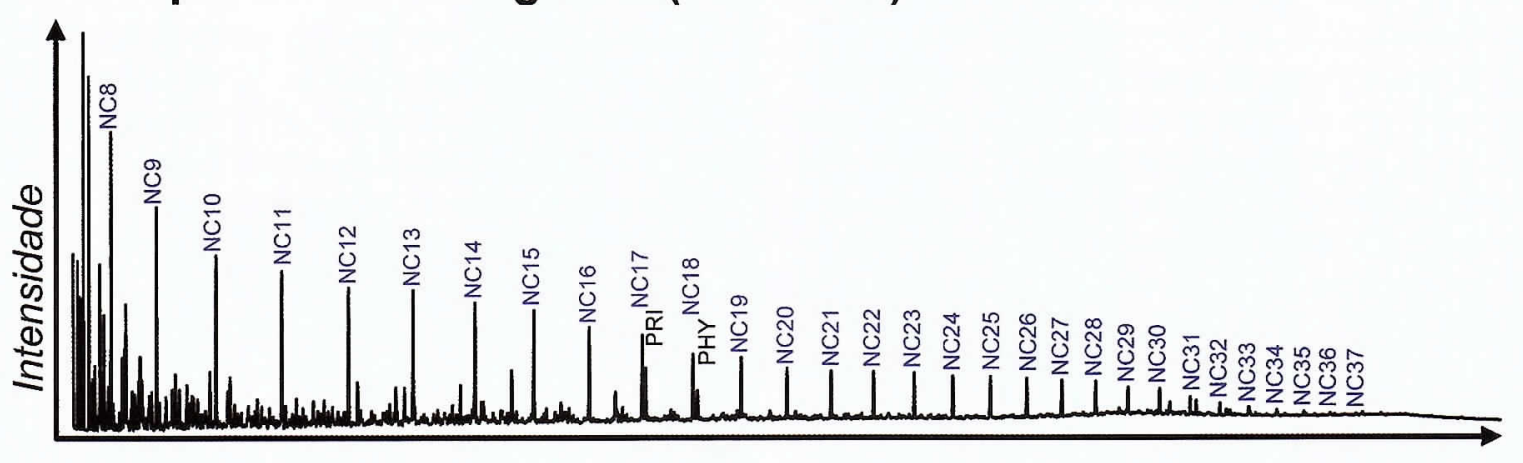

Tempo de retenção

Figura 5 - Exemplo de cromatograma gasoso whole oil de um óleo preservado. As parafinas lineares são os picos predominantes, enquanto as cadeias ramificadas (como por exemplo pristano - PRI, e fitano - PHY) assim como as cadeias cíclicas e compostos aromáticos são minoritários. 
coluna capilar, e com a mesma programação de temperatura (Kaufman et al. 1990). Estes procedimentos foram estabelecidos para evitar que variações analíticas fossem incorporadas as amostras. Segundo Hwang \& Baskin (1994), a precisão analítica dos cromatógrafos situa-se entre 1 e $3 \%$. De acordo com os mesmos autores, diferenças entre razões de picos com variação maior que $5 \%$, desde que sejam tomados os cuidados supra citados, podem significar heterogeneidades composicionais do óleo no reservatório.

Após a análise cromatográfica é necessária a integração dos picos obtidos, onde os valores serão utilizados para a aplicação da metodologia fingerprint whole oil. A vantagem deste método é que somente o cromatograma gasoso é suficiente para o estudo. Por outro lado, o processo é manual, a análise não é quantitativa, e não identifica nominalmente cada composto, além de ser necessário um maior tempo para a integração dos picos, o que acarreta uma maior possibilidade de erro. A figura 7 mostra o exemplo de um cromatograma obtido com a aplicação do método fingerprint whole oil, com os picos identificados numericamente.

Alternativamente, foi testada, no Centro de Excelência em Geoquímica (CEGEQ), resultado da parceria entre a COPPE/UFRJ (Instituto Alberto Luiz Coimbra de pós-graduação e pesquisa de engenharia/ Universidade Federal do Rio de Janeiro) e a gerência de geoquímica do Petrobras/Cenpes/PDEXP (Centro de pesquisas da Petrobras), a utilização do sistema CARBURANE®, para auxiliar nos estudos de Geoquímica de Reservatórios. O sistema CARBURANE® é um software de processamento de dados de cromatografia gasosa que permite a análise detalhada de hidrocarbonetos na faixa entre 5 e 20 átomos de carbono, com identificação e quantificação automática destes compostos. Comparativamente ao método cromatográfico tradicional empregado, além da maior rapidez na emissão dos resultados cromatográficos, pois é realizado em um sistema com reversão de fluxo, permite a análise somente da fração de interesse, diminuindo assim o tempo da corrida cromatográfica, eliminando ainda a necessidade de excessiva manipulação dos cromatogramas. Essa maior automação reduz a incerteza do método de análise inerente à seleção subjetiva de variáveis de integração por parte do analista. É uma ferramenta poderosa visto que permite a aplicação de parâmetros geoquímicos de interesse, identificando e quantificando os isômeros utilizados na definição destes parâmetros na composição dos óleos estudados. A figura 8 mostra o exemplo de um cromatograma obtido com a utilização do sistema CARBURANE® (Ferreira et al. 2006).

Para esta análise o cromatógrafo deve ser equipado com uma pré-coluna e uma válvula para reversão de fluxo (backflush), responsável pelo descarte da fração $n \mathrm{C}_{20+}$ e a rampa de aquecimento é de $1,1^{\circ} \mathrm{C} / \mathrm{min}$. É utilizado injetor por vaporização com divisão de fluxo e detector por ionização em chama de hidrogênio (DIC). O perfil cromatográfico obtido para cada amostra pode ser empregado como elemento de distinção entre elas, e cada composto é mensurado em porcentagem em peso

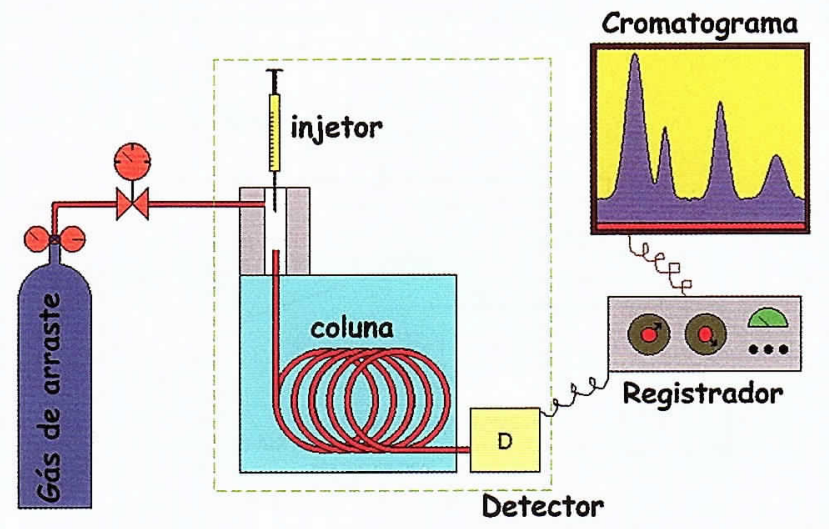

Figura 6 - Esquema de funcionamento de um cromatógrafo a gás.

(peso do composto para $100 \mu \mathrm{g}$ do óleo total). São identificados e quantificados aproximadamente 536 hidrocarbonetos na faixa entre 5 e 20 átomos de carbono. Este grande grupo de dados é empregado em conjunto com o perfil cromatográfico acarretando maior robustez na caracterização da variação composicional ao longo da coluna de óleo nos reservatórios.

\section{CROMATOGRAFIA EM FASE GASOSA ACOPLADA} A ESPECTROMETRIA DE MASSAS (CG-EM) Esta técnica é a principal ferramenta para análise dos biomarcadores, que são considerados os fósseis orgânicos preservados no óleo. Os fragmentogramas mais utilizados são o m/z 191 (terpanos) e m/z 217 (esteranos), pois apresentam as famílias mais abundantes de biomarcadores policíclicos saturados, em uma faixa de $\mathrm{C}_{27}$ $\mathrm{a} \mathrm{C}_{35}$. Outros fragmentogramas típicos podem ser o $\mathrm{m} / \mathrm{z}$ 123 (série dos secohopanos), m/z 177 (terpanos desmetilados), $\mathrm{m} / \mathrm{z} 231$ (metil-esteranos) e m/z 259 (esteranos rearranjados). Normalmente, as amostras analisadas são frações de saturados, ou de aromáticos provenientes da cromatografia líquida.

A amostra deve ser diluída com aproximadamente $100 \mu \mathrm{L}$ de $n$-hexano. É feita a injeção automática de $1 \mu \mathrm{L}$ de amostra com injetor mantido a $300^{\circ} \mathrm{C}$. Esta é carreada pelo gás de arraste inerte (hélio) até o cromatógrafo. A amostra passa por uma coluna capilar de sílica fundida, com $60 \mathrm{~m}$ de comprimento, $0,25 \mathrm{~mm}$ de diâmetro interno, contendo uma fina película $(0,25 \mu \mathrm{m})$ de fase estacionária. A rampa de temperatura é de $55^{\circ}$ a $320^{\circ} \mathrm{C}$, sendo que de $55^{\circ}$ a $150^{\circ} \mathrm{C}$, aplica-se um gradiente de $20^{\circ} \mathrm{C} / \mathrm{min}$ e de $150^{\circ}$ a $320^{\circ} \mathrm{C}$, de $1,5^{\circ} \mathrm{C} / \mathrm{min}$. Cada um dos componentes é transferido a uma interface, a $310^{\circ} \mathrm{C}$, localizada entre o cromatógrafo e o espectrômetro de massas. No espectrômetro de massas a amostra passa primeiramente por uma fonte de íons, onde recebe um bombardeio de elétrons com energia de $70 \mathrm{eV}$, ocorrendo a formação dos íons moleculares. Depois a amostra é encaminhada a um analisador quadrupolo, onde pode ser analisado um íon específico ou um conjunto de íons através de suas razões massa/carga. Por último, a amostra atinge o detector de massas ele- 


\section{Cromatograma gasoso (Fingerprint Whole oil)}

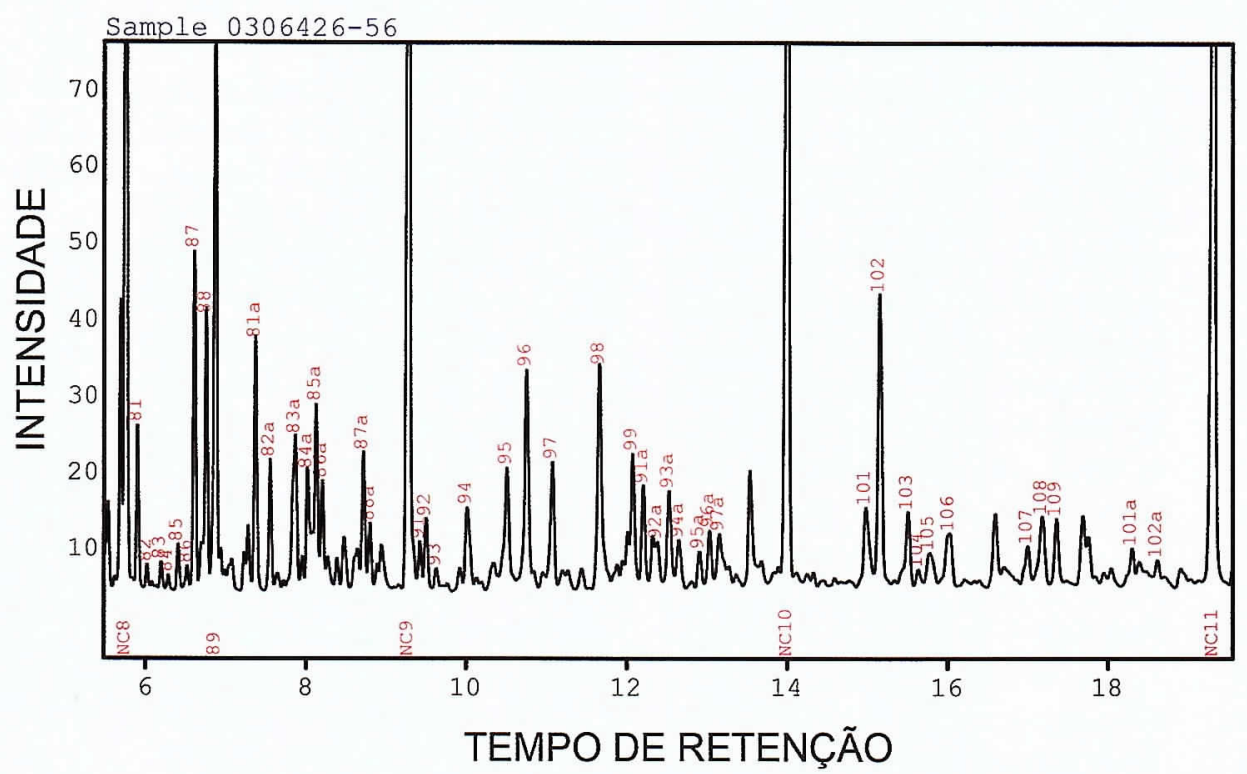

Figura 7 - Exemplo de um cromatograma obtido com a aplicação do método fingerprint whole oil, com os picos identificados numericamente.

\section{Cromatograma gasoso (CARBURANE)}

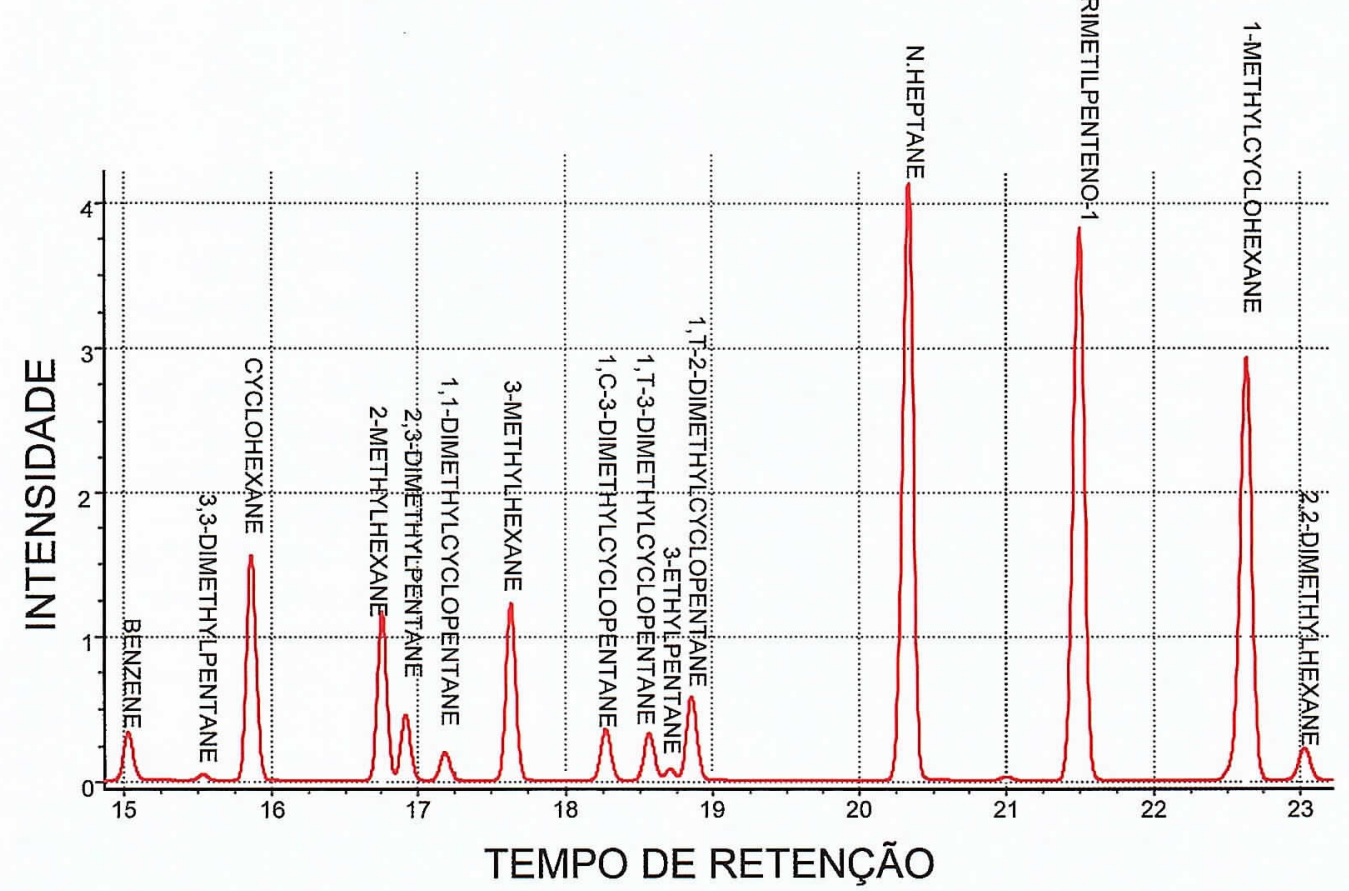

Figura 8 - Exemplo de um cromatograma obtido com a utilização do sistema CARBURANE®, com os picos identificados nominalmente.

tromultiplicador, que transforma os íons moleculares (ou fragmentos) em corrente elétrica, que ao ser enviada para a estação de trabalho emite o registro na forma de um cromatograma de massas.
ISÓTOPOS ESTÁVEIS DE CARBONO A razão ${ }^{13} \mathrm{C} /{ }^{12} \mathrm{C}$ é utilizada para medir o fracionamento isotópico em processos genéticos, associados à geradora, e pós-genéticos, relacionados a transformações secun- 
dárias. Os resultados da composição isotópica total de carbono são expressos na forma de $\delta^{13} \mathrm{C}$, onde $\delta=[(\mathrm{Ra}$ - Rp)/Rp] x $10^{3}$, onde $\mathrm{Ra}$ e $\mathrm{Rp}$ referem-se à razão isotópica ${ }^{13} \mathrm{C} /{ }^{12} \mathrm{C}$ da amostra e do padrão, respectivamente. Portanto, os valores medidos representam o desvio em relação ao padrão internacional $\mathrm{PDB}$, calibrados a um padrão secundário como o NBS 19 oil.

Para a determinação isotópica de carbono de um óleo, deve ser feita uma análise elementar e espectroscopia de massas para a razão isotópica (EA-IRMS). Pesam-se cerca de $200 \mu \mathrm{g}$ de amostra, em cápsulas de estanho. Estas cápsulas são acondicionadas em um amostrador automático, onde são purgadas em fluxo contínuo de hélio. A amostra é transferida para dentro de um tubo vertical de quartzo, onde ocorre a oxidação. Este tubo contém óxido de cromo, óxido de cobalto e prata. A temperatura é de $900^{\circ} \mathrm{C}$, e o hélio é enriquecido temporariamente com oxigênio puro e ocorre a oxidação da amostra pela reação flash combustion. São formados então $\mathrm{CO}_{2}$, água e compostos nitrogenados. Os compostos nitrogenados devem ser eliminados, em específico o $\mathrm{N}_{2} \mathrm{O}$, que tem massa 44 e pode interferir no pico do $\mathrm{CO}_{2}$ (que também apresenta massa 44). Então, a amostra passa por um forno de redução a $680^{\circ} \mathrm{C}$, contendo cobre e óxido de cobre, onde os compostos nitrogenados são eliminados. A água formada na oxidação fica retida em um trap de anidrônio (perclorato de magnésio). $\mathrm{O} \mathrm{CO}_{2}$ e o $\mathrm{N}_{2}$ são separados em uma coluna cromatográfica e transferidos para uma interface. Nesta unidade, $\mathrm{o} \mathrm{CO}_{2}$ é diluído com hélio e transferido ao espectrômetro de massas. Então as moléculas de $\mathrm{CO}_{2}$ entram em uma fonte de íons, onde são bombardeadas com feixe perpendicular de elétrons a $70 \mathrm{eV}$, formando $\mathrm{CO}_{2}^{+}$. O íon $\mathrm{CO}_{2}^{+}$pode apresentar massa 44,45 ou 46 , dependendo da combinação dos isótopos $\left(\mathrm{C}^{13} / \mathrm{C}^{12}\right.$ e $\mathrm{O}^{16} /$ $\mathrm{O}^{18}$ ). Cada íon formado é encaminhado a um coletor pré-determinado, através de campos magnéticos específicos. O resultado é então ampliado e comparado com o resultado do gás de referência, para o cálculo de $\delta$.

Métodos Matemáticos A base de dados utilizada nos estudos de Geoquímica de Reservatórios é proveniente dos resultados das análises geoquímicas onde, através de uma interface computacional, são reportados em números e apresentados em tabelas. A qualidade dos dados de entrada para a Geoquímica de Reservatórios é imprescindível, visto que as diferenças entre óleos de diversas partes de um reservatório, quando oriundos de uma mesma rocha geradora é muito pequena (Horstad \& Larter 1997). Partindo-se desta premissa, antes de ser realizada alguma análise a respeito de um conjunto de dados é necessário certificar-se que os dados são robustos e que fornecerão resultados confiáveis.

A análise exploratória de dados possui importância estratégica em qualquer técnica de processamento de dados. As características estatísticas do conjunto de dados de entrada determinarão a qualidade e confiabilidade estatística dos resultados de saída. A presença de outliers (valores que apresentam grande afastamento em relação aos das demais amostras), de variáveis dotadas de naturezas matemáticas distintas, diferentes grandezas e/ou multicorrelacionadas entre si são fatores determinantes nos resultados dos processamentos realizados. Desta forma, a análise exploratória é aplicada a fim de detectar outliers, bem como eliminar os dados ausentes buscando reduzir possíveis inconsistências nos dados.

Assim, a metodologia definida para a análise estatístico-exploratória dos dados originais consolida-se nos seguintes processos: (a) Análise geral do conjunto de dados alvo a partir do cálculo da média, valores mínimo e máximo, e desvio padrão para cada variável; (b) Verificação da presença de outliers em cada variável;(c) Verificação de valores ausentes em cada variável, e posterior exclusão do caso; (d) Transformação dos dados através de padronização ou de normalização.

A técnica de transformação utilizada para uniformizar os dados antes da análise de agrupamento (cluster analysis) é a padronização (standardization), embora a normalização (divisão de todos os valores da variável em questão pelo valor máximo) também possa ser empregada. A técnica de padronização apresenta como premissa transformar as variáveis de modo que as mesmas apresentem médias iguais a zero e desvios médios absolutos iguais a um (Sharma, 1996), segundo a equação (2):

$$
z_{i f}=\frac{x_{i f}-m_{f}}{s_{f}}
$$

onde:

$z_{i f}$ é o valor padronizado para o valor $x_{i f}$

$x_{i f}$ é o valor a ser padronizado.

$m_{f}$ é a média da variável $f$.

$s_{f}$ é o desvio padrão da variável $f$.

O emprego da padronização evita que durante a análise de cluster as diferentes variáveis contribuam com graus de influência variada decorrentes dos diferentes pesos associados. Porém, ainda para caracterização e visualização dos dados, gráficos do tipo estrela são construídos. No gráfico de estrela os eixos representam os valores das razões calculadas entre picos adjacentes ou próximos. Os picos são selecionados de acordo com a maior diferença entre estes nas amostras estudadas (um cromatograma gasoso de um óleo pode apresentar até 500 picos, porém apenas uma pequena porção destes são realmente empregados para discriminar grupos de óleos). O emprego de razões permite compensar a variação entre os valores unitários dos picos nas diferentes amostras, variações estas inerentes ao volume injetado e alterações de linha de base. Estas razões podem ser diferentes de um estudo para o outro de acordo com as características composicionais dos óleos dos reservatórios amostrados.

A repetitividade do método tem valores em torno de $1-3 \%$, logo diferenças acima de $5 \%$ já são consideradas heterogeneidades associadas ao óleo e são raras dentro de um mesmo reservatório podendo ser 
atribuídas a zonas não comunicadas (Hwang \& Baskin, 1994).

APLICAÇÕES A Geoquímica de Reservatórios abrange estudos de casos em uma vasta área na indústria do petróleo. A identificação da continuidade dos reservatórios de petróleo é uma das aplicações mais comuns, pois uma questão fundamental durante o desenvolvimento de um campo de petróleo é determinar se este produzirá como um enorme tanque cheio de óleo ou como reservatórios pequenos e separados. O nível de compartimentação dos reservatórios define o número e a posição de poços necessários para otimizar a drenagem e recuperação de petróleo do campo. Devido a compartimentação afetar os tipos de facilidades necessárias para explotar o campo, e conseqüentemente o projeto econômico, é crucial identificar a continuidade lateral dos reservatórios, tão cedo quanto possível, ainda durante a fase de avaliação do campo. Os itens descritos a seguir exemplificam dois estudos de casos.

Identificação de Continuidade Lateral dos Reservatórios Com o objetivo de aplicar a técnica de Geoquímica de Reservatórios para a investigação da existência de variações composicionais laterais que possam representar compartimentação no reservatório, foi realizado um estudo com 26 amostras de óleo empregando a metodologia de cromatografia gasosa utilizando o software CARBURANE®. As amostras de óleo são provenientes de um mesmo campo, com grau API na faixa entre $22,5-42,8^{\circ}$, recuperadas nos três principais reservatórios deste, sendo duas amostras do reservatório $\mathrm{A}$, seis amostras do reservatório $\mathrm{B}$ e as demais do reservatório $\mathrm{C}$.

De posse dos resultados analíticos verificou-se a existência de diferenças na composição química dos óleos. Para estimar essa variação foi realizada a análise de agrupamento (Cluster Analysis, Complete Linkage Method and Euclidian Distance) com parâmetros envolvendo as quantidades de hidrocarbonetos cíclicos, parafínicos e ramificados. Outra maneira de visualizar este agrupamento é através do diagrama em estrela que envolve os mesmos parâmetros, corroborando este resultado (Fig. 9).

O dendograma obtido indica três grupos diferentes, representados pelas amostras dos reservatórios $\mathrm{A}, \mathrm{B}$ e $\mathrm{C}$, sugerindo que as três zonas produtoras amostradas, não possuem continuidade na região dos poços estudados. No reservatório A similaridade composicional entre as duas amostras indica ausência de barreira ao fluxo de fluidos entre os dois poços neste reservatório. Da mesma maneira, a grande similaridade composicional dos óleos amostrados no reservatório B sugere continuidade lateral neste reservatório, na região dos poços avaliados. Por outro lado, no reservatório C, os óleos amostrados são em maior parte composicionalmente diferentes, sugerindo compartimentação no reservatório. Entretanto, existe a possibilidade de comunicação lateral do reservatório $\mathrm{C}$ na região dos poços $\mathrm{C} 6$ e C7, e também entre os poços $\mathrm{C} 8$ e $\mathrm{C} 9$, devido a maior simi- laridade composicional entre as amostras recuperadas nestes poços.

Portanto, a variação composicional dos óleos avaliada pela metodologia de cromatografia gasosa com software CARBURANE® pode ser utilizada como ferramenta adicional na caracterização da continuidade de reservatórios, promovendo subsídios para o gerenciamento da produção em campos de petróleo.

\section{Identificação de Continuidade Vertical dos Reser-} vatórios A compartimentação vertical ocorre quando reservatórios estão separados por regiões de baixa permeabilidade, tais como folhelhos, cimentação carbonática, ou mesmo por tar mats (Smalley \& England, 1992). Neste exemplo foram estudadas amostras de óleo recuperadas em diferentes intervalos produtores de sete poços perfurados durante a fase exploratória de um campo de petróleo. A metodologia utilizada segue os principios definidos por Slentz (1981) e Kaufman et al. (1990) onde os gráficos estrela apresentados correlacionam os valores das razões normalizadas das alturas dos picos identificados.

Para avaliar a continuidade vertical dos reservatórios foram correlacionadas as amostras dos intervalos produtores em cada poço separadamente. As amostras recuperadas em diferentes profundidades nos poços 1, 2, 3, 4 e 5 são composicionalmente similares em cada poço, o que sugere continuidade vertical do reservatório nestes poços (Fig. 10).

Por outro lado, nos poços 6 e 7 a ausência de similaridade composicional entre as amostras indica uma possível barreira ao fluxo de fluidos entre os pontos amostrados nos respectivos reservatórios (Fig. 11). Em relação as três amostras recuperadas no poço 6 nas profundidades $2817 \mathrm{~m}, 2874 \mathrm{~m}$ e $3143 \mathrm{~m}$, somente as duas primeiras apresentam similaridade composicional. Este resultado indica que o intervalo superior não possui continuidade vertical com o reservatório produtor da zona inferior, no referido poço (Fig. 11a). No caso do poço 7 as amostras correspondentes ao intervalo superior (reservatório A; $2850-2851 \mathrm{~m}, 2824 \mathrm{~m}, 2824,5 \mathrm{~m}$, $2850,5 \mathrm{~m}, 2886,5 \mathrm{~m}, 2887 \mathrm{~m}$ ) apresentam similaridade composicional indicando a continuidade vertical deste reservatório (Fig. 11b). Entretanto, as recuperadas nas profundidades 2943,5m, 2971,6-2972,6m e 2972,1m (reservatório B) são composicionalmente diferentes das representantes do reservatório A, o que indica barreira ao fluxo de fluidos entre o reservatório $\mathrm{A}$ e o reservatório B no poço mencionado. Adicionalmente, a amostra recuperada em 2943,5m é composicionalmente diferente daquelas obtidas em $2971,6 \mathrm{~m}$ e $2972,1 \mathrm{~m}$ o que sugere que existe barreira ao fluxo de fluidos e/ ou diferenciação vertical no reservatório B no intervalo amostrado (Fig. 11b).

Estes dados podem ser usados como uma ferramenta adicional na caracterização de reservatórios e promovem subsídios para aprimorar a avaliação e desenvolvimento da produção de campos de petróleo, como por exemplo sugerindo a completação de poços em mais de uma zona de produção. 


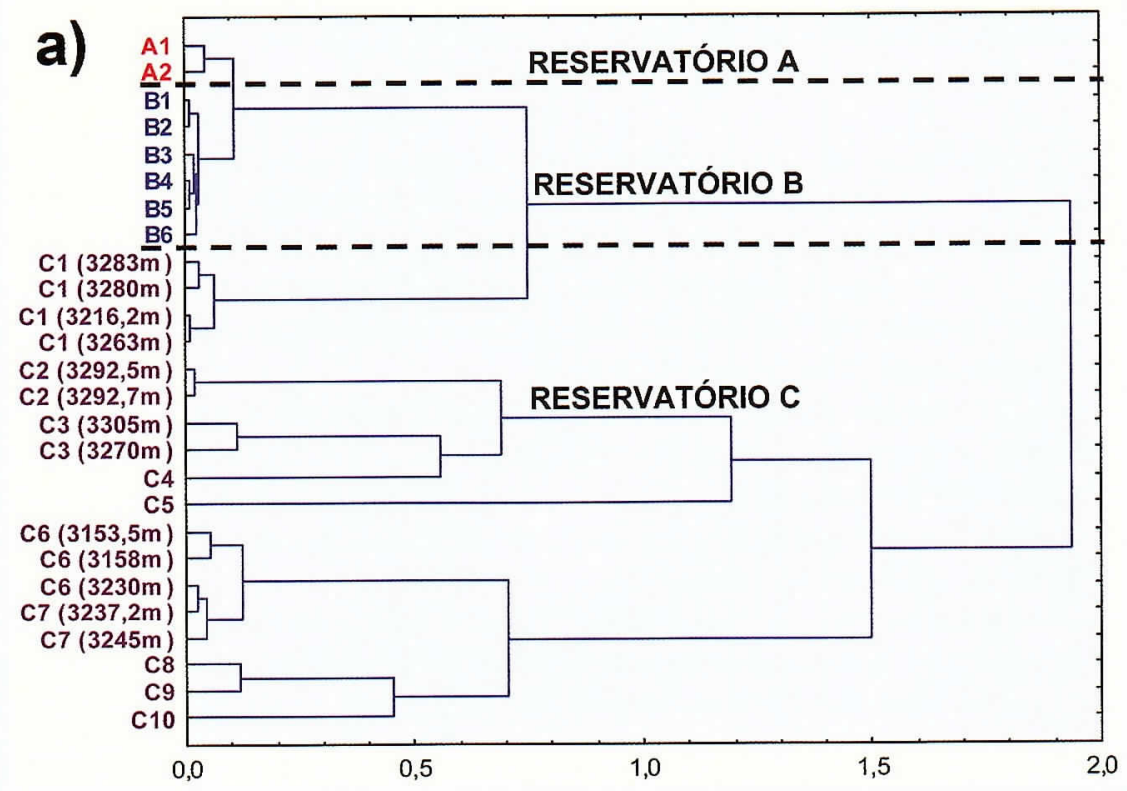

b)

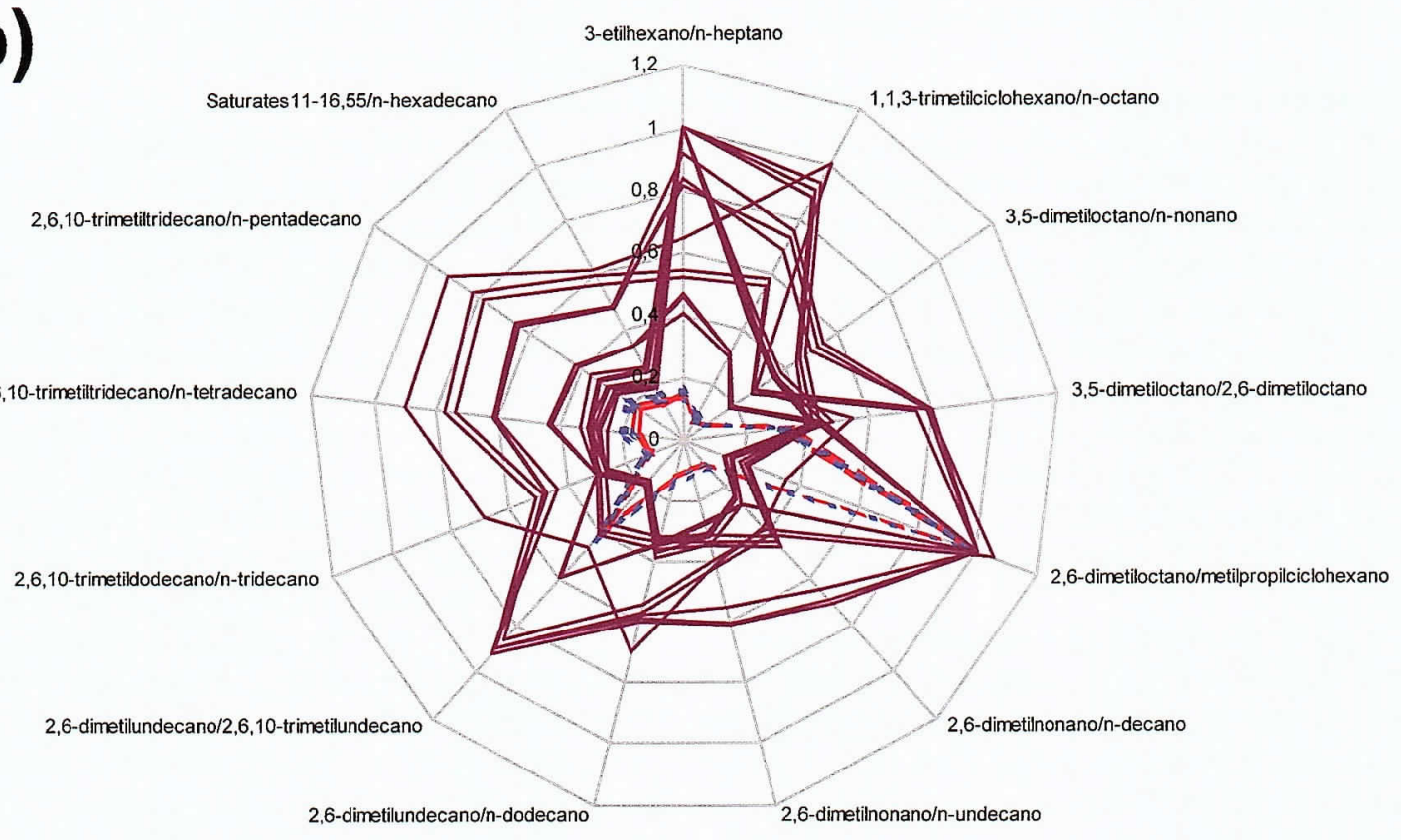

. $-\operatorname{Res} . \mathrm{A}=-\operatorname{Res} . \mathrm{B}-\operatorname{Res} . \mathrm{C}$

Figura 9 - Comparação entre as amostras provenientes dos três reservatórios (a) Análise de Agrupamento (acima), e (b) diagrama de estrela (abaixo).

CONTROVÉRSIAS E DIVERGÊNCIAS A base da Geoquímica de Reservatórios consiste na hipótese de que o petróleo de uma acumulação é tão bem misturado que a composição é praticamente homogênea. Compartimentos separados são aventados quando a variação composicional de óleos, amostrados em diferentes locais, alcança um valor limite de aceitação, especialmente quando dados de pressão dos reservatórios indicam uma possível compartimentação. Entretanto, existem situações em que os dados obtidos podem induzir a interpretações errôneas que devem ser cuidadosamente avaliadas.

Uma importante implicação do trabalho de En- gland \& Mackenzie (1989) é que em muitos casos, a variação composicional lateral inerente ao processo de preenchimento do reservatório pode não ser eliminada. Se uma variação lateral de densidade é observada no reservatório é possível que não tenha havido tempo suficiente para que os fluidos se homogeneizassem, assim é necessário sempre integrar as interpretações geoquímicas com os dados geológicos para reconhecer esses casos, e assim evitar a identificação de barreiras inexistentes (Smalley et al. 2004). Por outro lado, em alguns casos, gradientes de densidade laterais podem ser eliminados sem a homogeneização da composição química do petróleo, porque muitas combinações de 

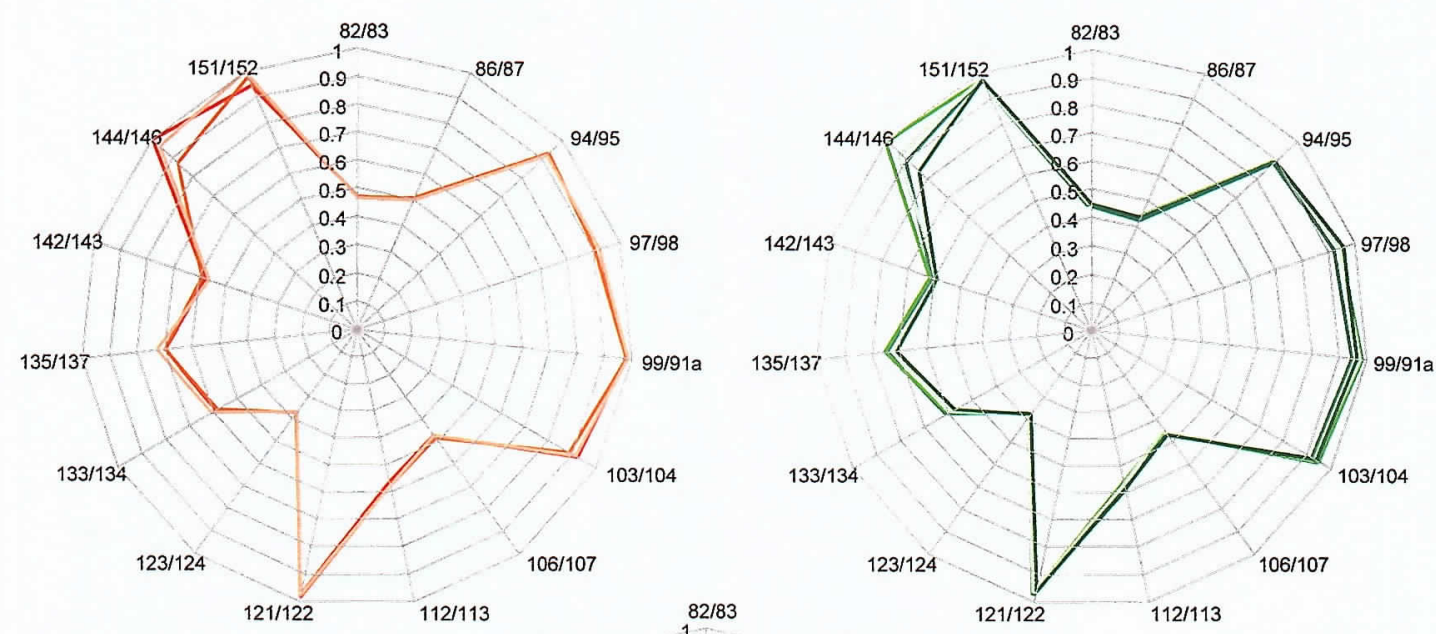

-Poço $1(2745.8 \mathrm{~m}$
- Poço $1(2825 \mathrm{~m})$
- Poço 1 (2831.5)

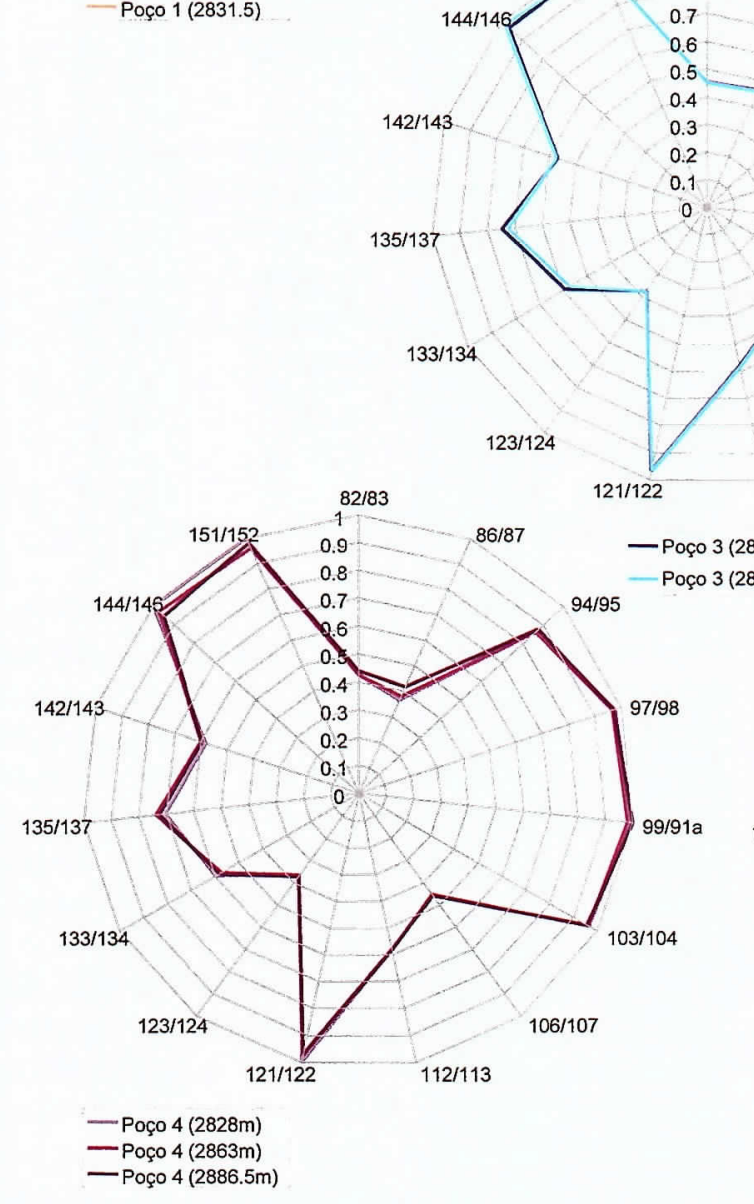

86/87 -Poço 2 $2795 \mathrm{~m})$

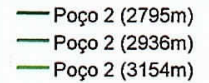
Poço $2(3154 \mathrm{~m})$
Poço 2 (superficie)
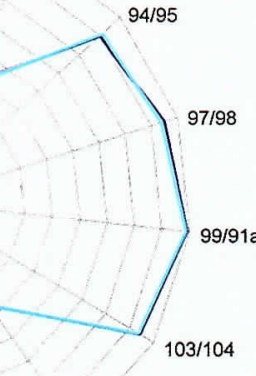

$106 / 107$
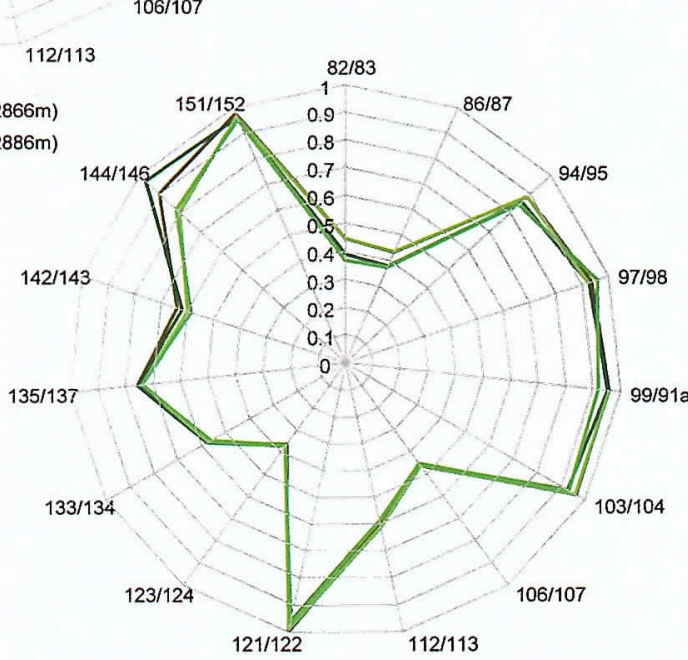

-Poço $5(2840 \mathrm{~m})$
- Poço $5(2841 \mathrm{~m})$
-Poço $5(2903,5 \mathrm{~m})$
- Poço $5(2904 \mathrm{~m})$

Figura 10 - Diagrama de estrela entre as amostras dos intervalos produtores em cada poço separadamente. As amostras recuperadas nos poços 1, 2, 3, 4 e 5 são composicionalmente similares o que sugere continuidade vertical do reservatório.

composições químicas podem produzir fluidos com mesma densidade (England 1990).

Existem outros processos que podem resultar em divergências nos fundamentos de Geoquímica de Reservatórios, como por exemplo: se um reservatório de petróleo lateralmente contínuo for preenchido por um fluido, após um período de tempo, este será homogeneizado resultando em um fluido de composição constante ao longo do tempo. Entretanto, se ocorrer um falhamento no bloco, promovendo a compartimentação do reservatório, após o fluido ter alcançado o equilíbrio, a "impressão digital" dos óleos será a mesma, embora o reservatório não esteja lateralmente em comunicação (England, 2007). Contrariamente, Beeunas et al. (1999) apresentaram o estudo onde foram observadas heterogeneidades composicionais nos óleos acumulados em 

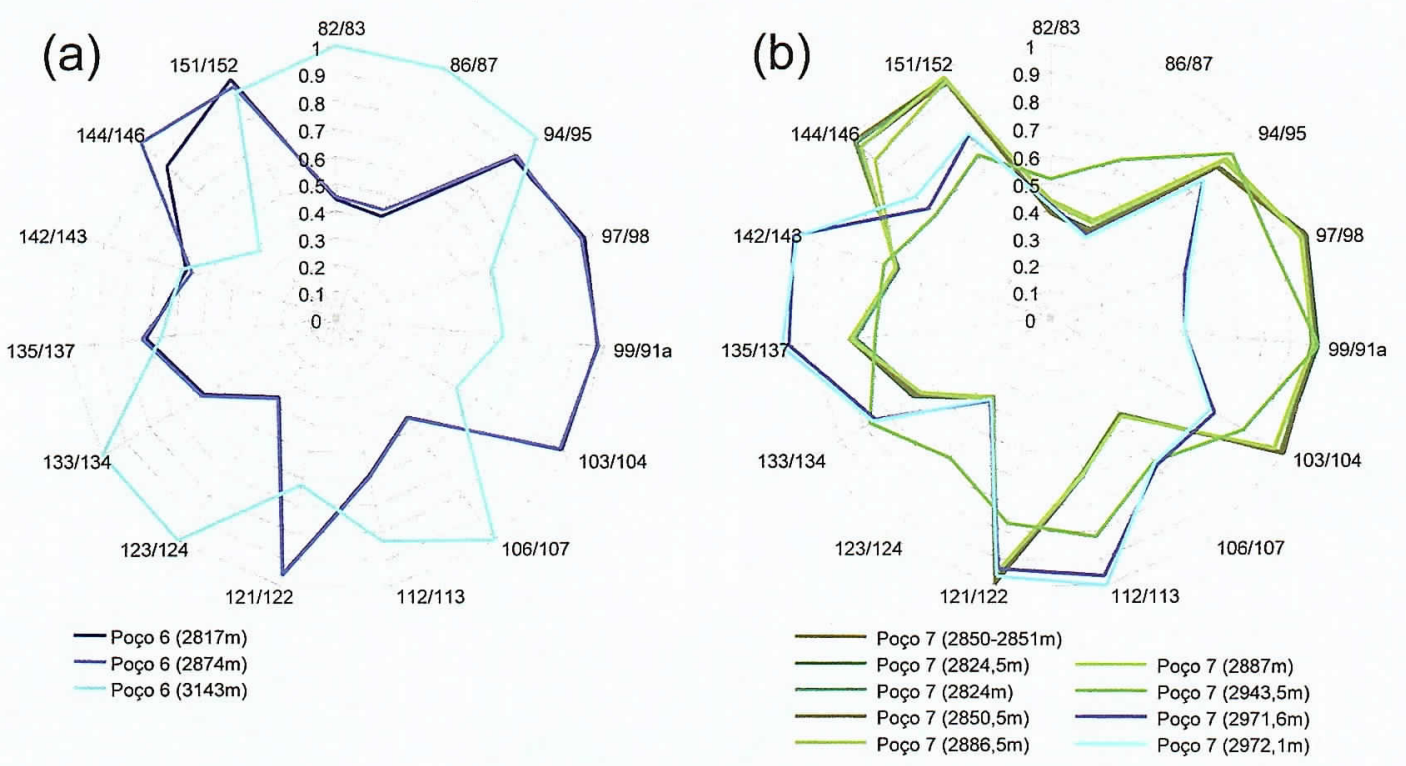

Figura 11 - Diagrama de estrela representativo das amostras dos intervalos produtores em cada poço separadamente. (a) Diagrama de estrela entre as amostras recuperadas no poço 6 mostrando similaridade composicional somente entre duas amostras (2874m e $2817 \mathrm{~m}$ ). (b) Diagrama de estrela entre as amostras recuperadas no poço 7 mostrando a similaridade composicional das amostras correspondentes ao intervalo superior (reservatório 1) e a heterogeneidade composicional destas amostras com as do Reservatório 2.

um único reservatório. Uma das explicações apontadas pelos autores para esta situação incomum é o preenchimento do reservatório por uma carga muito recente de óleo, como indicam a história de soterramento e os modelos de maturação térmica.

Outra possível ambigüidade na interpretação é o aparecimento de um efetivo gradiente composicional vertical em campos que aparentemente estão em completa comunicação, quando avaliados por dados de pressão. Estes gradientes são observados também nas propriedades globais dos óleos como: densidade API, razão gás-óleo (RGO) e o ponto de bolha, e é freqüentemente designado como segregação gravitacional. Para resultados mais conclusivos na avaliação da continuidade lateral de reservatórios deve ser verificado cuidadosamente se as medidas de profundidades referem-se a um único poço (em uma única coluna de óleo), ou a vários poços que penetram o reservatório em profundidades diferentes. Nesta última hipótese avalia-se a relação da variação composicional lateral do óleo com a profundidade. Portanto, nestas situações, os gradientes composicionais podem ser devidos a um único reservatório, ou a variações composicionais devido à barreira ao fluxo de fluidos em um campo extenso, ou mesmo a combinação dos dois (Stainforth 2004).

Pelo exposto, conclui-se que o entendimento dos processos que controlam a heterogeneidade composicional do fluido antes, durante e depois do preenchimento do reservatório deve ser cuidadosamente avaliado, cotejando sempre que possível outras informações geológicas. Reforça, portanto a percepção de Westrich et al. (1999): "Nós precisamos saber quando isto funciona, quando não, e porque".

CONCLUSÕES O foco da Geoquímica de Petróleo tem sido ampliado nos últimos anos, além da exploração tem sido desenvolvidos trabalhos na área de avaliação, desenvolvimento e produção de reservatórios de petróleo. Como resultado surgiu uma subdisciplina, a Geoquímica de Reservatórios, que envolve o estudo de fluidos nos reservatórios e sua interação com as rochas reservatório, e pode ser visto como uma relação entre a geologia e a engenharia de reservatórios.

Heterogeneidades composicionais são inerentes ao processo de preenchimento de reservatórios e freqüentemente resultam em fluidos que não estão em equilíbrio químico. Difusão e forças direcionadas por densidade tendem a estabelecer o equilíbrio mecânico e químico, em taxas que dependem das distâncias nas quais as instabilidades existem, assim como da permeabilidade do reservatório. Em geral, o equilíbrio químico é rapidamente alcançado em uma coluna de óleo individual sem barreiras verticais ao fluxo de fluidos. Por outro lado, gradientes composicionais laterais em larga escala tendem a persistir por períodos significativos de tempo geológicos, enquanto o equilíbrio mecânico em colunas de fluido é rapidamente atingido em reservatórios contínuos.

As variações composicionais de petróleo podem ser observadas mediante um perfil cromatográfico individual através das abundâncias distintas dos compostos que estão distribuídos entre as parafinas normais. Kaufman et al. (1990) desenvolveram um método sensível para reconhecer diferenças em cromato- 
gramas gasosos da fração leve do petróleo conhecido como fingerprint whole oil. Em geral, o cromatograma gasoso de óleo total (whole oil) como um todo não tem suficiente precisão para distinguir óleos de composição similar. O método desenvolvido por eles visa procurar diferenças entre os compostos menos abundandantes, como as parafinas ramificadas, os compostos naftênicos, e os aromáticos. Posteriormente, a cromatografia gasosa CARBURANE® substituiu a cromatografia gasosa (fingerprint whole oil) devido a primeira apresentar vantagens analíticas e interpretativas. O fluxo geral deste procedimento resume-se em: (1) coleta das amostras, (2) análise cromatográfica, (3) seleção dos picos, (4) correlação dos óleos e (5) interpretação geológica.

É fundamental como em qualquer outra aplicação da Geoquímica de Reservatórios a disponibilidade de amostras preservadas, principalmente de óleo. Independentemente do foco da investigação proposta é imprescindível contar com um conjunto de amostras confiáveis de modo a não introduzir nas conclusões um fator imponderável.

Casos de sucessos com a utilização da Geoquímica de Reservatórios foram apresentados neste trabalho, indicando que a Geoquímica de Reservatórios é uma técnica efetiva que pode ser usada como uma ferramenta na descrição, avaliação e desenvolvimento de reservatórios, assim como na exploração regional e também auxiliando a produção por um custo relativamente baixo.

Em síntese, para aprimorar a Geoquímica de Reservatórios é necessário reconhecer a origem das heterogeneidades composicionais cada vez mais sutis em amostras de óleos, e para isso são imprescindíveis: (a) avanço dos métodos analíticos para a determinação da composição dos fluidos; (b) implementação de modelos físicos, químicos e numéricos para a interpretação das diferenças composicionais em termos da história da bacia e da conectividade do reservatório; (c) acoplamento da modelagem de bacias, preenchimento do reservatório e modelos de processos de mistura; (d) aplicação em estudos de casos.

Assim como em muitas áreas científicas, quanto mais sabemos, mais questões são postuladas. Geoquímica de Reservatórios não é uma exceção, e está claro que existe muito trabalho a ser feito nesta fascinante área (England \& Larter, 2004).

Agradecimentos À Petrobras pela possibilidade de realização destas pesquisas e a permissão para divulgação deste trabalho. Adicionalmente, gostaríamos de agradecer ao geólogo José Roberto Cerqueira pela leitura crítica deste artigo e pelas valiosas sugestões.

\section{Referências}

Beeunas M.A., Baskin D.K., Schoell M. 1999. Application of gas geochemistry for reservoir continuity assessment and identification of fault seal breakdown, South Marsh Island 61, Gulf of Mexico. In: AAPG Hedberg Research Conference "Natural Gas Formation and Occurrence", Durango, Colorado.

Cerqueira J.R. \& Trindade L.A. F. 1995. Geoquímica de Reservatórios: métodos e aplicações. In: Sociedade Brasileira de Geoquímica, Congresso Brasileiro de Geoquímica, 5, Congresso de Geoquímica dos Países de Língua Portuguesa, 3, Niteroi, RJ., CD-Rom.

Rangel M. D. 2003. Geoquímica de Reservatório aplicada aos Campos de Fazenda São Rafael e Fazenda Santa Luzia, Bacia do Espírito Santos, Brasil. Dissertação de mestrado, COPPE/UFRJ, Rio de Janeiro, 297 p.

England W.A. 1990. The organic geochemistry of petroleum reservoirs. Organic Geochemistry, 16(1-3):415-425.

England W.A. 2007. Reservoir geochemistry - A reservoir engineering perspective. Journal of Petroleum Science and Engineering, 58(3-4): 344-354.

England W.A. \& Mackenzie A.S. 1989. The geochemistry of petroleum. Geologische Rundschau, Special Volume: Evolution of Sedimentary Basins, 78(1).

England W.A. \& Larter S.R. 2004. Understanding petroleum reservoirs: towards an integrated reservoir engineering approach. Introduction. In: J.M. Cubbit, W.A. England, S.R. Larter (eds.) Understanding petroleum reservoirs: towards an integrated reservoir engineering approach. Geological Society Special Publication, 237:1-5. The Geological Society of London.
England W.A., Muggeridge A.H., Clifford P.J., Tang Z. 1995. Modelling density-driven mixing rates in petroleum reservoirs on geological time-scales, with application to the detection of barriers in the Forties Field (UKCS) In: J.M. Cubbit \& W.A. England (eds.) The Geochemistry of Reservoirs. Geological Society Special Publication, 86:185201. The Geological Society of London.

Ferreira A.A., Torres C.L., Rangel M.D., Aquino Neto F.R. 2006. Quantitative analysis of light hydrocarbons (C5 to C20) using CARBURANE®: Fundamentals and application in reservoir geochemistry. In: ALAGO, Congress on Organic Geochemistry, Salvador, Brazil, extended abstract, p.49-51.

Firozoozabadi A., Dindoruk B., Chang E. 1996. Areal and Vertical composition variation in hydrocarbon reservoirs: formulation and one-D binary results. Entropie, 198/199:109-118.

Firozoozabadi A. 1999. Thermodynamics of Hydrocarbon Reservoirs. New York, McGraw-Hill, 353 p.

Halpern H. 1995. Development and application of light hydrocarbon based star diagrams. American Association of Petroleum Geologists Bulletin, 79:801-815.

Høier L. \& Whitson C.H. 2001. Compositional grading - theory and practice. SPE Reservoir Evaluation \& Engineering, 4(6):525-535.

Horstad I., Larter S.R., Dypvik H., Aagaard P., Bjornvik A.M., Johansen P.E., Eriksen S. 1990. Degradation and maturity controls on oil field petroleum column heterogeneity in the Gullfaks field, Norwegian North Sea. Organic Geochemistry, 16(1-3):497-510. 
Horstad I. \& Larter S. R. 1997. Petroleum migration, alteration, and remigration within Troll field Norwegian North Sea, AAPG Bulletin, 81:222-248.

Hwang R.J. \& Baskin D.K. 1994. Reservoir connectivity and oil homogeneity in a large-scale reservoir. In: AlHusseini M. (ed.) Middle East Petroleum Geoscience. Manama, Bahrain, Geo 94, v.2, p. 529-541.

Hwang R.J., Ahmed A.S., Moldowan J.M. 1994. Oil composition variation and reservoir continuity: Unity Field, Sudan: Org. Geochem., 21:171-188.

Jarvie D., Hill R., Mango F. 2001. Effect of inorganic constituents on light hydrocarbon composition and compound distributions of crude oils. In: International Meeting on Organic Geochemistry, $20^{\text {th }}$, Nancy, France, Abstract, p.10-14.

Kaufman R.L., Ahmed A.S., Elsinger R.J. 1990. Gas Chromatography as a development and production tool for fingerprinting oils from individual reservoirs: applications in the Gulf of Mexico, In: Schumaker D. \& Perkins B.F. (eds.) Annual Research Conference of the Society of Economic Paleontologists and Mineralogists, $9^{\text {th }}$, New Orleans, USA, p. 263-282.

Larter S.R. \& Aplin A.C. 1995. Reservoir geochemistry: methods, applications and opportunities. In: J. M. Cubitt e W.A. England (eds). The Geochemistry of Reservoirs. Geological Society Special Publications n. 86, p.5-32.

Lindberg F.A., Ahmed A.S., Bluhm D.C.T. 1990. The role of oil-to-oil correlation in the development of the Safah field (abstract). AAPG Bulletin, 74:705.

Mango F. D. 1990a. The origin of cycloalkanes in petroleum. Geochimica et Cosmochimica Acta Geology, 54:23-27.

Mango F.D. 1990b. The origin of light hydrocarbons in petroleum: a kinetic test of the steady-state catalytic hypothesis. Geochimica et Cosmochimica Acta Geology, 54:1315-1323.

Mango F.D. 1994. The origin of light hydrocarbons in petroleum: ring preference in the closure of carbocyclic rings. Geochimica et Cosmochimica Acta Geology, 58:895901.

Mango F.D. 1997. The light hydrocarbons in petroleum: a critical review. Organic Geochemistry, 26:417-440.

Nederlof P.J., Gijsen M.A., Doyle M.A. 1994. Application of reservoir geochemistry to field appraisal. In: M.I. AlHusseini (ed.) The Middle East Petroleum Geosciences Geo '94. Bahrain, vol.2. Gulf-Petrolink, p. 709-722.

Nederlof P.J.R., Van der Veen F.M., Van den Bos G.A. 1995. Application of reservoir geochemistry in Oman. In: J. O. Grimalt, \& C. Dorronsoro (eds.) Organic Geochemistry: Developments and Applications to Energy, Climate, Environment and Human History. Selected Papers from the 17th International Meeting on Organic Geochemistry, Donostia-SanSebastián, The Basque Country, Spain:
San Sebastian, p. 329-331.

North F.K. 1985. Petroleum Geology. Boston, UNWIN HYMAN, 631p.

Ross L.M. \& Ames R.L. 1988. Stratification of oils in Columbus basin off Trinidad. Oil \& Gas J., 86(26):72-76.

Sharma S. 1996. Applied Multivariate Techniques. University of South Carolina, 493p.

Slentz L.W. 1981. Geochemistry of reservoir fluids as unique approach to optimum reservoir management. In: SPE, Middle East Oil Technical Conference, Manama, Bahrain, Paper No. 9582, p. 37-51.

Smalley P.C. \& England W.A. 1992. Assessing reservoir compartmentalization during field appraisal: How geochemistry can help. In: SPE, Annual Technical Conference and Exhibition (ATCE), Washington, DC, Paper No. 25005, p. 423-431.

Smalley C., England W.A., Muggeridge A., Abacioglu Y., Cawley S. 2004. Rates of reservoir fluid mixing: implications for interpretation on fluid data. In: Cubitt J.M., England W.A., Larter S.R. (eds.) Understanding Petroleum Reservoirs: Towards an Integrated Reservoir Engineering and Geochemical Aprroach. Geological Society, London, Special Publications, p. 99-113.

Stainforth J.G. 2004. New insights into reservoir filling and mixing processes. In: Cubitt J.M., England W.A., Larter S.R. (eds.) Understanding Petroleum Reservoirs: Towards an Integrated Reservoir Engineering and Geochemical Aprroach. Geological Society, London, Special Publications, p. 115-132.

Sundararaman P., Patterson B.A., Udo O.T. 1995. Reservoir geochemistry: applications and case studies in Nigeria. In Grimalt J.O., \& Dorronsoro C. (eds.) Organic Geochemistry: Developments and Applications to Energy, Climate, Environment and Human History. Selected Papers from the 17th International Meeting on Organic Geochemistry, Donostia-SanSebastián, The Basque Country, Spain: San Sebastian, p. 369-371.

Thompson K.F.M. 1983. Classification and thermal history of petroleum based on light hydrocarbons. Geochimica et Cosmochimica Acta, 47:303-316.

Thompson K.F.M. 1988. Gas-condensate migration and oil fractionation in deltaic systems. Marine and Petroleum Geology, 5:237-246.

Westrich J.T., Fuex A.M., O'neal P.M., Halpern H.I. 1999. Evaluating Reservoir Architecture in the Northern Gulf of Mexico. SPE Reservoir Evaluation \& Engineering, 2(6):514-519.

Manuscrito BR 01

Submetido em 19 de dezembro de 2007 Aceito em 16 de março de 2008 